\title{
FOUR-LEVEL EN BLOC VERTEBRECTOMY: A NOVEL TECHNIQUE AND LITERATURE REVIEW
}

\section{VERTEBRECTOMIA EM BLOCO EM QUATRO NÍVEIS: NOVA TÉCNICA E REVISÃO DA LITERATURA}

\author{
Douglas Kenj Narazaki ${ }^{1}$, lucas P. Higino ${ }^{1}$, William Gemio Jacobsen Teixeira ${ }^{1}$, Ivan Dias da Rocha ${ }^{1}$, Alexandre Fogaça Cistante $^{2}$, \\ Tarcísio Eloy Pessoa de Barros Filho ${ }^{2}$
}

1. Hospital das Clínicas da Faculdade de Medicina da Universidade de São Paulo (IOT-HCFMUSP), Instituto de Ortopedia e Traumatologia, Spine Surgery Division, Spinal Tumors, São Paulo, SP Brazil.

2. Hospital das Clínicas da Faculdade de Medicina da Universidade de São Paulo (IOT-HCFMUSP), Instituto de Ortopedia e Traumatologia, Spine Surgery Division, Laboratory of Medical Investigation, São Paulo, SP, Brazil.

\section{ABSTRACT}

Objective: To demonstrate a novel technique for multilevel en bloc post-vertebrectomy reconstruction. Methods: A novel technique for en bloc multiple post-vertebrectomy reconstruction was used in a patient presenting for curative resection of Ewing's Sarcoma at the oncology center of a public university hospital. Results: The procedure described was feasible for en bloc resection of the four vertebrae. The reconstruction was acceptable and satisfactory in terms of mechanical stability and was without any neurological sequelae in the patient. Conclusion: The use of an allograft with a locked intramedullary nail was an adequate solution for reconstructing the anterior and medial spines after multilevel vertebrectomy. In addition, the association of four intramedullary nails provided stability to the reconstruction. Immediate benefits of the technique compared to other commonly used techniques were shorter hospitalization times and reduced surgical morbidity. Level of Evidence V, Clinical study of a new surgical technique and a literature review.

Keywords: Reconstructive Surgical Procedures. Spinal Neoplasms. Spine. Thoracic Surgery. Orthopedics

\section{RESUMO}

Objetivo: Demonstrar uma nova técnica de reconstrução por vertebrectomia em bloco multinível. Métodos: Descrição de uma reconstrução pós-vertebrectomia em bloco multinível, em paciente tratado num hospital oncológico público universitário, com indicação de ressecção curativa de sarcoma de Ewing. Resultados: 0 procedimento proposto foi viável para a ressecção em bloco de quatro vértebras e a reconstrução foi aceitável e satisfatória em termos de estabilidade mecânica, sem causar dano neurológico ao paciente. Conclusão: O uso de aloenxerto com parafuso intramedular bloqueado é uma solução adequada para a reconstrução da coluna anterior e medial após vertebrectomias multiníveis. Além disso, a associação de quatro parafusos intramedulares dá estabilidade à reconstrução. Benefícios imediatos da técnica são o tempo de hospitalização mais curto e a redução da morbidade cirúrgica, em comparação com outras técnicas, comumente utilizadas. Nível de Evidência $V$, Estudo clínico de nova técnica cirúrgica e revisão da literatura.

Descritores: Procedimentos Cirúrgicos Reconstrutivos. Neoplasias da Coluna Vertebral. Coluna Vertebral. Cirurgia Torácica. Ortopedia.

Citation: Narazaki DK, Higino LP, Teixeira WGJ, Rocha ID, Cristante AF, Barros Filho TEP. Four-level en bloc vertebrectomy: A novel technique and literature review. Acta Ortop Bras. [online]. 2018;26(6):406-10. Available from URL: http://www.scielo.br/aob.

\section{INTRODUCTION}

Around $5 \%$ to $10 \%$ of all primary malignant bone tumors occur in the vertebral spine. According to the literature, the mean survival is between six and eight months when the vertebral spine is affected by primary or metastatic tumors. ${ }^{1}$

In the past, malignant tumors of the vertebral spine were considered incurable, because achieving wide surgical margins appeared to be surgically impossible. For a long time, intralesional resection was the option for surgical treatment of tumors of the spine, but the results were oncologically poor. ${ }^{2}$
Ewing's Sarcoma is one of the most common forms of primary malignant bone tumors in children and adolescents. The most common primary sites of involvement are the pelvis, femur and tibia. Primary involvement of the spine is rare, with an incidence of only $5 \%$. $^{3,4}$

En bloc resection of primary malignant tumors of the vertebral spine with oncological surgical margins has attracted great interest, as it increases the survival rate and improves local control of the tumor. As a result, various total vertebrectomy techniques have been developed for tumors of the vertebral spine.

\section{All authors declare no potential conflict of interest related to this article.}


Greater development of this technique, called "total en bloc vertebrectomy", ${ }^{5}$ has revealed the possibility of achieving oncologically secure resection margins. Thus, the surgical option to improve both local control of the tumor and overall survival has become technically viable. ${ }^{5,6,7}$

En bloc resection is associated with a high rate of complications. On the other hand, it decreases the risk of local recurrence and mortality related to the tumor. En bloc resection is, therefore, a very demanding process, but it can be performed with an acceptable degree of safety. ${ }^{8}$

It is indicated in cases of aggressive malignant tumors and primary benign tumors of the vertebral spine, single metastatic tumors of primary tumor with favorable prognosis (good prognostic scores), and extracompartmental, multisegmental vertebral tumor manifestations, according to Tomita type $6 .{ }^{7}$ Contraindications include disseminated vertebral metastatic disease and detection of distant metastases in the staging investigation, and biologically unfavorable tumors or diffuse malignant tumors with primary systemic dissemination (Tomita score $<4-5$ points, Tokuhashi score $<12$ points). ${ }^{9,10}$

The main complication of multilevel en bloc resection associated with reconstruction is posterior instrument failure. Although these patients with instrument failure present back pain, the neurological complications are not catastrophic. ${ }^{11}$

In regard to irrigation, we have two main concerns in these cases of en bloc vertebral resection: spinal cord ischemia after ligation of the segmental arteries, and excessive perioperative bleeding. Interruption of the artery of Adamkiewicz, the most important artery, does not adversely affect neurological function. We strongly advocate that our surgeons sacrifice up to three pairs of segmental arteries, even including the artery of Adamkiewicz, if necessary. The recent development of new preoperative embolization techniques ensures a more aggressive, more extensive, and safer embolization for this type of procedure..$^{12,13}$

Total en bloc vertebrectomy can be performed through the anterior and posterior approaches, isolated or combined, or through a single posterior approach. For most one- or two-level tumors, the posterior approach is sufficient. In patients with three or more levels of involvement, the neovascular structures are initially approached via the anterior route, then en bloc resection is performed via the posterior route, with instrumentation of the pedicle screws and anterior reconstruction. ${ }^{14}$

There are some options for post-vertebrectomy reconstruction; some studies demonstrate that a system of replacement of the vertebral body through a carbon fiber interbody cage has low complications, but is limited to just a few levels involved in the en bloc resection. ${ }^{15}$

Nowadays, artificial bone grafts are more commonly used, without a significant decrease in the rate of incorporation when compared with the previously used techniques, i.e. autologous grafts. However, the reconstructions involving fewer resected levels are also limited. Distributing the load across a greater number of screws ensures stability and decreases the danger of failure and loosening of the main implant. ${ }^{16}$ The aims of this work are to present a new technique for four-level en bloc post-vertebrectomy reconstruction, and to carry out a literature review on multilevel en bloc vertebrectomies.

\section{CASE REPORT}

In December 2014, a 32-year-old patient presenting progressive low back pain associated with paresthesia of the lower limbs for four years, who had undergone surgical treatment three times, was selected for treatment with en bloc multilevel post-vertebrectomy reconstruction. In the first surgery, performed three years previously, a partial resection of the tumor was performed, and histopathological study of the surgical pieces, with diagnosis of Ewing's
Sarcoma. The patient received adjuvant treatment with twenty-five radiotherapy sessions and seventeen cycles of chemotherapy. In the second procedure, two years after the first, a new resection and laminectomy of T10-T12 were performed. After two months, there was a new recurrence, but another surgical intervention could not be carried out due to intraoperative hemorrhaging. Once again, the patient received adjuvant radiotherapy and chemotherapy. All these procedures were performed in other hospitals.

An MRI scan was taken of the thoracic-lumbar spine, eight months after the last surgery, revealing a suspected tumor mass due to local recurrence or residual progressive at the corresponding vertebral levels (Figure 1). The MRI showed a voluminous expansive lobulated lesion in the left-side foraminal regions of T10-T11 and T11-T12 and in the left pedicles and posterior portion of vertebral bodies T10, T11 and T12, with epidural lesional component of T9-L2, particularly in T11. The patient was then referred to our service.

The patient received neoadjuvant chemotherapy with ifosfamide and etoposide. The physical examination showed back pain in the thoracic-lumbar areas and decreased mobility of the thoracic-lumbar spine, without neurological defect, classified as Frankel D. In terms of prognosis, we used the Tomita score $(<4-5$ points) and the Tokuhashi index ( $<12$ points). ${ }^{9,10}$ There was no evidence of distance metastases in the staging. Our team decided to perform complete en bloc resection of the injured vertebrae (T10 to L1).

The new surgical technique was performed with the consent of the local ethics committee (Protocol IOT 1346) and the patient signed the Free and Informed Consent Form.

A total of three surgical interventions were performed at our service, over a period of 18 days (Figure 2). The first was via the posterior route, involving release of the fibrosis and dural sac, the second was a thoracoscopy for ligation of the segmental arteries, and the third, multilevel en bloc resection of four vertebrae and reconstruction via the posterior route.

\section{Surgical technique}

In the first intervention, via the posterior route, we made an incision with a spindle from $T 5$ to $L 5$, separating the erector spinae muscles from the bone structures. A previous laminectomy was observed at levels T10 to T12. Next, we inserted the pedicle screws in T5-T8 and L2- L5 bilaterally, extending the laminectomy and arthrectomies from $T 9$ to L1. There was also a previous pediculectomy from T10 to L1. Finally, we performed circumferential release of the dural sac, and ligated the roots from T9 to L1, bilaterally.

In the second intervention, 11 days after the first, we performed an anterior and thoracoscopic approach, with ligation of the segmental arteries of $\mathrm{T} 10$ to $\mathrm{T} 12$, bilaterally, by the thoracic surgery team. The patient was put under general anesthesia with selective intubation, and positioned lying on the right side. We performed mini-thoracotomies of $2.0 \mathrm{~cm}$, one on the midde-axilary line in the sixth left intercostal space, another on the axillary-posterior line in the seventh left intercostal space, and a final one on the axillary-posterior line in the ninth intercostal space. We used a 10.5 millimeter tube needle for optics of 10 and 30 millimeters.

We identified vertebral bodies T10, T11 and T12. We opened the parietal pleura of these bodies, and dissected the arterial and venous segmental branches. We ligated the proximal and distal segmental vessels with a metal clamp (LT300) and transected them by electrocauterization. We drained the pleural cavity with a thoracic drain, through the portal in the ninth intercostal space. The patient was then repositioned lying on the left side, and we performed the same technique to access the thoracic cavity, ligating the contralateral vessels. 


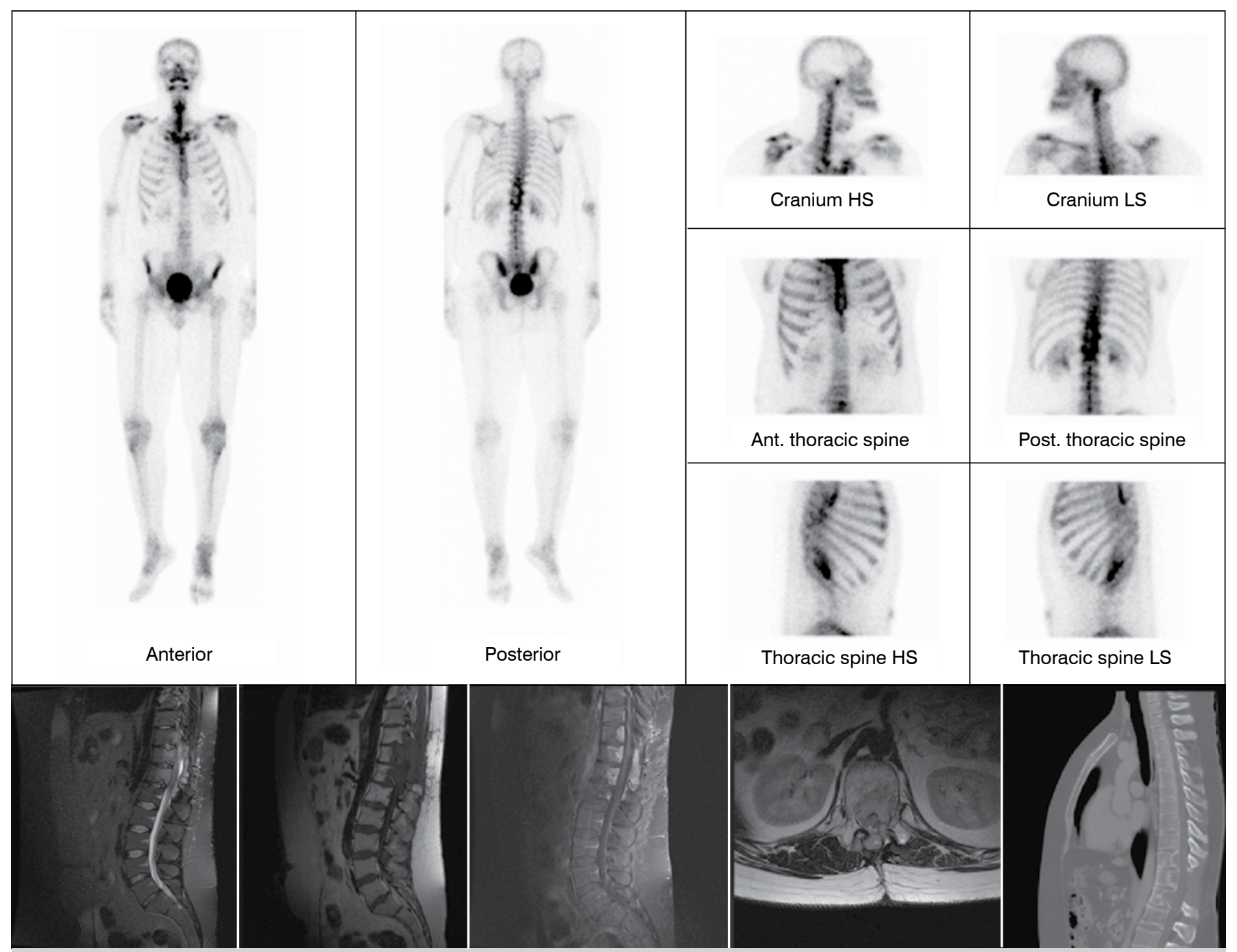

Figure 1. Preoperative scintigraphy $(A)$ and magnetic resonance imaging (MRI) (B to F) of the patient with Ewing's Sarcoma.

In the third and final surgical intervention, we performed total en bloc resection of the tenth thoracic vertebra at the first lumbar vertebral level, via the posterior approach.

\section{Resection}

The important surrounding structures were released manually, from the anterior surface of the vertebral spine, without violating the tumor. We moved the parietal pleura to the side of the vertebrae, and observed the bilateral ligature of segmental arteries T10, T11 and $\mathrm{T} 12$ that had been done in the second intervention. We ligated segmental arteries from L1, bilaterally, under direct vision. Next, we released the diaphragm and the aortic artery from the spine by manual blunt dissection. We placed spatulas ("shoes") between the aorta and the spine. We then dissected from T9-T10 and L1$\mathrm{L} 2$, using disc tweezers, chisels and scalpel, and removed the longitudinal posterior and anterior ligaments. Finally, we resected the four vertebrae (T10 to L1) en bloc, working clockwise.

\section{Reconstruction}

1. Preparation of the allograft with $0.9 \%$ saline solution, nail fixation (Interlocking Orthofix Inc.) and blocking of the intramedullary system, performed on a sterile auxiliary surgical table.

2. Placement of the graft system + nail, through fixation from vertebrae T9 and $\mathrm{L} 2$ with an awl, inserting the allograft with an humeral interlocking nail without locking it, sliding the nail initially distally and then sliding it proximally after placing between vertebrae T9 and L1, locking the locking screw in the allograft, and rotating the nail for lordosis in conjunction with the graft.

B.3. Compression of the systems of four nails on the allograft + interlocking. It is important to emphasize that the fact that the interlocking of the humerus is slightly curved helped maintain the sagittal alignment of the spine.

After inserting two JP drains, we closed the wound.

The total surgery time was 22 hours, with replacement of 4 RBC (red blood cell) concentrates and 1 FFP (fresh frozen plasma), to replace the loss of approximately $4000 \mathrm{ml}$ of blood. The histopathological exam showed a piece measuring $12.2 \times 5.2 \times 5.2$ centimeters, including the tumor lesion, measuring $9.2 \times 2.2$ centimeters, occupying the region of vertebral bodies T10 to L1. Ewing's Sarcoma was confirmed, with caudal and cranial resection margins free of tumor, and the presence of angiolymphatic invasion.

\section{Postoperative management}

In the postoperative period (Figure 3), the patient remained in the intensive care unit (ICU) for three weeks, presenting the main complication of infection of the surgical site, which was resolved by two surgical cleanings, ten days apart, the first one week after the primary surgery and the second nine days after the reconstruction, 


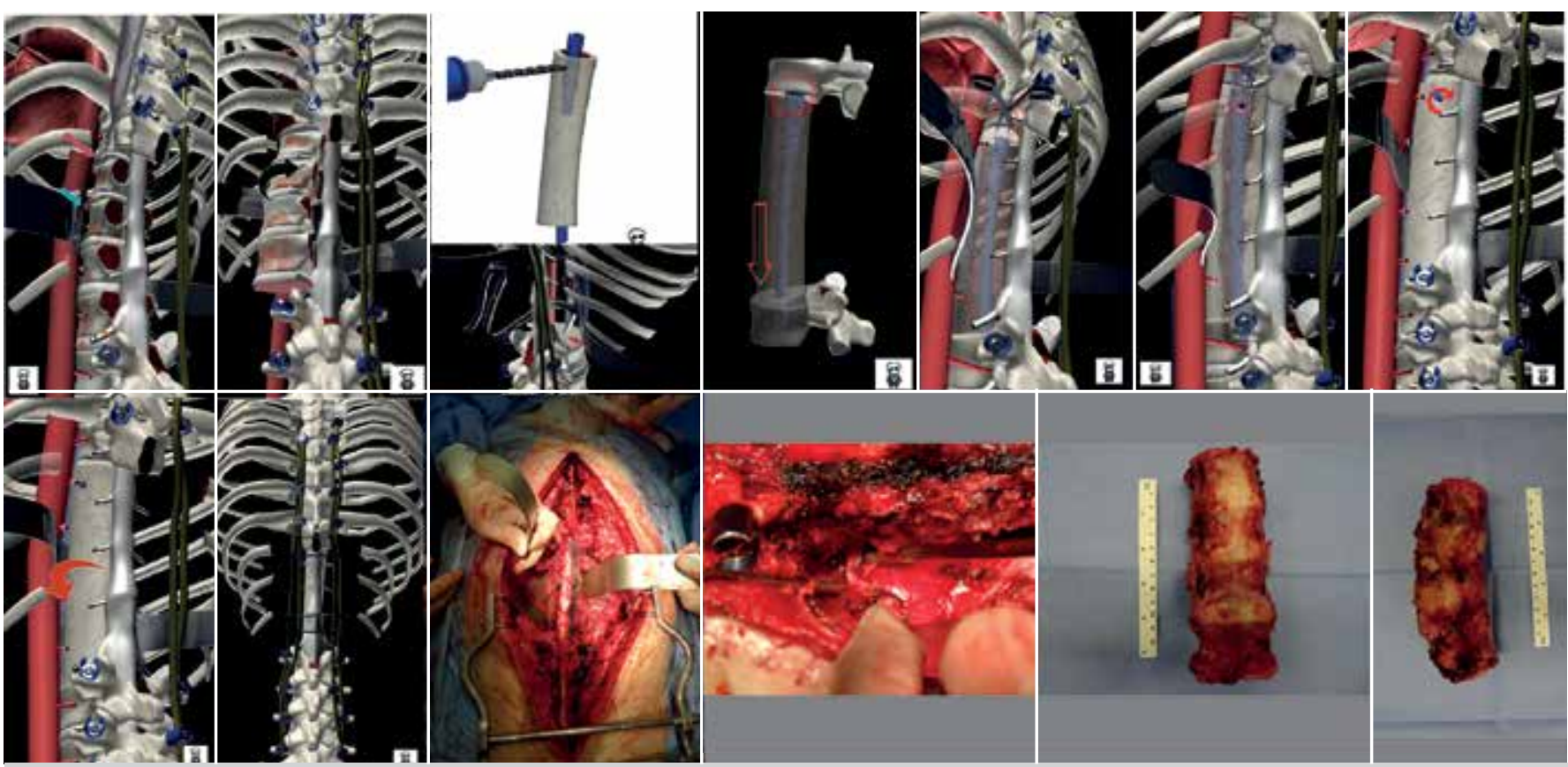

Figure 2. Operative imaging of the patient with Ewing's Sarcoma: operative planning (A-J), photographs of the surgery (K-Q) and photographs of the excised pieces $(R, S)$.
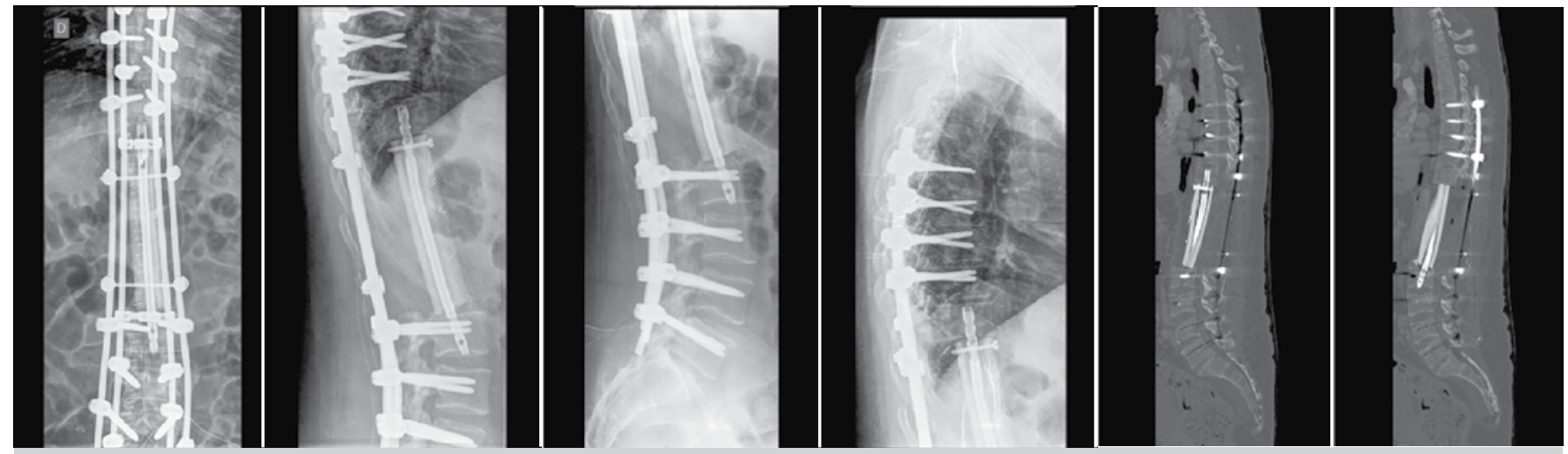

Figure 3. Postoperative radiographs (A-D) and magnetic resonance imaging (MRI) (5-6) of the patient with Ewing's Sarcoma.

together with the use of antibiotics (piperacillin/tazobactan and linezolid for three months).

We opted for early mobilization on postoperative day one, with the assistance of a trained physiotherapist. The patient was encouraged to perform walking training on day 10 after the final surgical procedure. On postoperative day 20, we encouraged the patient to walk unaided, and indicated discharge from hospital.

We performed follow-up at one, two, three and six months postoperative. In the postoperative period, no adjuvant therapy was given, due to maximum toxicity having been reached by the neoadjuvant chemotherapy. At the six-month follow-up, there was no evidence of local recurrence or distant metastatic lesions, and the patient presented good neurological function.

\section{DISCUSSION}

Different authors have reported surgical approaches by the combined access route, presenting low rates of complications. ${ }^{17,18}$ The reconstruction techniques differ in various aspects; there is the option to use a double nail system, as opposed to the four nail system, although the latter offers more stability. In terms of the number of levels used in the fixation, there is controversy over longer fixations, with three or four levels above and below generally being indicated for more pathological bones, and shorter fixations when two levels are involved.

In relation to the reconstruction, the most common alternatives are mesh cage, expandable cage, vascularized fibula, and allograft, selected based on the size of the en bloc vertebrectomy. In the case described, owing to the fact that it was an extensive resection, our choice was for the allograft. We also opted to use an interlocking nail to fix the graft, seeking to block a nail within the allograft to avoid migration or pistoning of same, and movement of the allograft. Our preference is for a combined posterior approach for multilevel en bloc resections. To achieve tumor-free margins, en bloc excision of the tumor in the thoracic-lumbar vertebral spine requires extension of the resection margins, including all the structures that could be affected and are potentially resectable, such as the intervertebral discs above the affected vertebrae, in the cranial-caudal direction. The incidence of complications is significantly higher in revision surgeries, compared with patients who have not undergone previous surgery. The rate of local recurrence in these revision surgeries is 
even more significant ${ }^{19}$ because it is very difficult to recognize and obtain tumor free margins.

The most extensive resection described in the literature was of five vertebrae, with a marginal resection achieved. A case was reported involving a patient with a large chordoma of the thoracic spine, who underwent a successful spondylectomy of 5 levels with bilateral chest wall resection for en bloc resection without neurologic compromise. ${ }^{20}$

The reconstruction through the system of four bars and posterior pedicle screws associated with allograft of the femur fixed with locked humeral nail offers good conditions for bone fusion, despite the fact that we have not yet obtained postoperative follow-up data during these six months.

Patients who have undergone previous surgeries tend to present higher rates of complications. Local recurrence worsens the prognosis and quality of life. This fact shows that the prognosis is related mainly to how the first treatment is done.

Thus, a realistic assessment of the oncological usefulness of surgical interventions, and an assessment of the surgical viability, must precede any consideration in the indications for en bloc multilevel resection, in order to justify the risk to the patient. Usually, this decision is taken as part of an interdisciplinary approach, involving the experience and therapeutic options of all the teams involved in the oncological treatment of these patients.

Our technique enables both resection and stabilization via the combined posterior approach. The advantage of this procedure is the ability to control the posterior and anterior vascular nerve structures and the mediastinal and visceral structures, during the resection. It is important to highlight that the use of the nail (Interlocking Orthofix Inc) improves the reliability of mechanical stability of multilevel en bloc resections, adequately accommodating the transition anatomy of the thoracic-lumbar spine and decreasing the risk of migration when associated with the posterior four-nail system.

The case report highlights the feasibility and safety of resection multilevel block, although our short follow-up is an aspect to be improved for the further development of the technique. Therefore, experience in surgery and techniques for the reconstruction of the vertebral column as well as a multidisciplinary approach of the tumor, are prerequisites for a good result.

AUTHORS' CONTRIBUTIONS: DKN (0000-0001-7895-4830)*, WGJT (0000-0001-9036-629X)*, and AFC (0000-0002-7797-5274)* conducted the bibliographic search and evaluated the statistical analysis. LPH (0000-0003-4008-3667)* and IDR (0000-0001-6533-4528)* performed data collection and were involved in patient follow-up. TEPBF (0000-0002-0819-7712)* was the main contributor in the drafting of the manuscript, being responsible for the revision of the manuscript and contributing to the intellectual concept of the study. *ORCID (Open Researcher and Contributor ID).

\section{REFERENCES}

1. Kelley SP, Ashford RU, Rao AS, Dickson RA. Primary bone tumours of the spine: a 42-year survey from the Leeds Regional Bone Tumour Registry. Eur Spine J. 2007; 16(3):405-9.

2. 2. Kawahara N, Tomita K, Murakami H, Demura S. Total en bloc spondylectomy for spinal tumors: surgical techniques and related basic background. Orthop Clin North Am. 2009:40(1):47-63.

3. Bernstein M, Kovar H, Paulussen M, Randall RL, Schuck A, Teot LA, et al. Ewing's sarcoma family of tumors: current management. Oncologist. 2006;11(5):503-19.

4. Ewing J. The Classic: Diffuse endothelioma of bone. Proceedings of the New York Pathological Society. 1921;12:17. Clin Orthop Relat Res. 2006;450:25-7.

5. Roy-Camille R, Saillant G, Mazel C. Plating of thoracic, thoracolumbar, and lumbar injuries with pedicle screw plates. Orthop Clin North Am. 1986;17(1):147-59.

6. Talac R, Yaszemski MJ, Currier BL, Fuchs B, Dekutoski MB, Kim CW, et al. Relationship between surgical margins and local recurrence in sarcomas of the spine. Clin Orthop Relat Res. 2002;(397):127-32.

7. Tomita K, Kawahara N, Baba H, Tsuchiya H, Fujita T, Toribatake Y. Total en bloc spondylectomy. A new surgical technique for primary malignant vertebral tumors. Spine (Phila Pa 1976). 1997;22(3):324-33.

8. Yoshioka K, Murakami H, Demura S, Kato S, Kawahara N, Tomita K, et al. Clinical outcome of spinal reconstruction after total en bloc spondylectomy at 3 or more levels. Spine (Phila Pa 1976). 2013;38(24):E1511-6.

9. Tomita K, Kawahara N, Kobayashi T, Yoshida A, Murakami H, Akamaru T. Surgical strategy for spinal metastases. Spine (Phila Pa 1976). 2001;26(3):298-306.

10. Tokuhashi $Y$, Matsuzaki $\mathrm{H}$, Oda H, Oshima M, Ryu J. A revised scoring system for preoperative evaluation of metastatic spine tumor prognosis. Spine (Phila Pa 1976). 2005;30(19):2186-91.

11. Matsumoto M, Watanabe K, Tsuji T, Ishii K, Nakamura M, Chiba K, et al. Late instrumentation failure after total en bloc spondylectomy. J Neurosurg Spine. 2011;15(3):320-7
12. Murakami H, Kawahara N, Tomita K, Demura S, Kato S, Yoshioka K. Does interruption of the artery of Adamkiewicz during total en bloc spondylectomy affect neurologic function? Spine (Phila Pa 1976). 2010;35(22):E1187-92.

13. Nambu K, Kawahara N, Kobayashi T, Murakami H, Ueda Y, Tomita K. Interruption of the bilateral segmental arteries at several levels: influence on vertebral blood flow. Spine (Phila Pa 1976). 2004;29(14):1530-4.

14. Hsieh PC, Li KW, Sciubba DM, Suk I, Wolinsky JP, Gokaslan ZL. Posterior-only approach for total en bloc spondylectomy for malignant primary spinal neoplasms: anatomic considerations and operative nuances. Neurosurgery. 2009;65(6 Suppl):173-81; discussion 181.

15. Disch AC, Schaser KD, Melcher I, Luzzati A, Feraboli F, Schmoelz W. En bloc spondylectomy reconstructions in a biomechanical in-vitro study. Eur Spine J. 2008; 17(5):715-25

16. Akamaru T, Kawahara N, Sakamoto J, Yoshida A, Murakami H, Hato T, et al. The transmission of stress to grafted bone inside a titanium mesh cage used in anterior column reconstruction after total spondylectomy: a finite-element analysis. Spine (Phila Pa 1976). 2005;30(24):2783-7.

17. Abe E, Sato K, Tazawa H, Murai H, Okada K, Shimada Y, et al. Total spondylectomy for primary tumor of the thoracolumbar spine. Spinal Cord. 2000;38(3):146-52.

18. Boriani S, Bandiera S, Donthineni R, Amendola L, Cappuccio M, De lure F, et al. Morbidity of en bloc resections in the spine. Eur Spine J. 2010;19(2):231-41.

19. Krepler $P$, Windhager R, Bretschneider W, Toma CD, Kotz R. Total vertebrectomy for primary malignant tumours of the spine. J Bone Joint Surg Br. 2002;84(5):712-5.

20. Sciubba DM, Gokaslan ZL, Black JH 3rd, Simmons O, Suk I, Witham TF, et al. 5-Level spondylectomy for en bloc resection of thoracic chordoma: case report. Neurosurgery. 2011;69(2 Suppl Operative):onsE248-55. 